\title{
Anesthesia-related mortality and morbidity in Japan (1999)
}

\author{
Yasuo Kawashima ${ }^{1}$, Norimasa $\mathrm{SeO}^{2}$, Kiyoshi Morita ${ }^{3}, \mathrm{Kazuo} \mathrm{Irita}^{4}$, Yasuhide IwaO ${ }^{5}, \mathrm{Koichi}_{\text {Tsuzaki }}{ }^{6}$, \\ Tsutomu KobaYashi ${ }^{7}$, Yasuyuki Goto ${ }^{8}$, and Shuji Dohi ${ }^{9}$ \\ ${ }^{1}$ Department of Anesthesiology, Teikyo University School of Medicine, 2-11-1 Kaga, Itabashi-ku, Tokyo 173-8605, Japan \\ ${ }^{2}$ Department of Anesthesiology and Critical Care Medicine, Jichi Medical School, Tochigi, Japan \\ ${ }^{3}$ Department of Anesthesiology and Resuscitology, Okayama University, Graduate School of Medicine and Dentistry, Okayama, Japan \\ ${ }^{4}$ Department of Anesthesiology and Critical Care Medicine, Graduate School of Medical Sciences, Kyushu University, Fukuoka, Japan \\ ${ }^{5}$ Department of Anesthesiology, Kyorin University School of Medicine, Mitaka, Tokyo, Japan \\ ${ }^{6}$ Department of Anesthesiology, School of Medicine, Keio University, Tokyo, Japan \\ ${ }^{7}$ Department of Anesthesiology and Intensive Care Medicine, Kanazawa University, Graduate School of Medical Science, Kanazawa, Japan \\ ${ }^{8}$ Sapporo Ichijyo Clinic, Sapporo, Japan \\ ${ }^{9}$ Department of Anesthesiology and Critical Care Medicine, Gifu University School of Medicine, Gifu, Japan
}

Key words Anesthesia $\cdot$ Cardiac arrest $\cdot$ Intraoperative complications $\cdot$ Risk management

\section{Introduction}

No nationwide statistical data on anesthesia-related mortality and morbidity have been compiled in Japan since the foundation of the Japanese Society of Anesthesiologists (JSA) in 1954, when modern anesthesiology was first introduced in Japan. The need to comprehensively examine cardiac arrest and other critical incidents due to anesthesia as well as their outcomes in Japan prompted the JSA Committee on Operating Room Safety (JSACORS) to begin an annual study in JSA Certified Training Hospitals (CTHs) in 1993.

In the first study, identical confidential questionnaires were sent to CTHs at the end of every year from 1994 to 1998 and collected in March of the following year. An average of $696 \pm 38$ (mean \pm SD) CTHs and $472608 \pm$ 93206 anesthesias per year (for a total of 2363038 anesthesias) were included in the study. The results have been published elsewhere [1-6].

For the studies since 1999, the JSACORS modified the questionnaire to achieve more detailed analysis of anesthesia-related mortality and morbidity. As a result, analysis of the effects of ASA physical status (ASA-PS), age group, surgical site, and anesthetic method became possible. Further, the principal causes of cardiac arrest and other critical incidents could be tabulated in four major categories: anesthetic management, intraoperative pathological events, preoperative complications,

Address correspondence to: Y. Kawashima

Received: May 7, 2002 / Accepted: July 26, 2002 and surgery. Six papers were published on the detailed analyses of the data in 1999 in Masui (Jpn J Anesthesiol), in Japanese with English abstracts [7-12]. This article is a comprehensive summary of the Annual Study of Anesthesia-Related Mortality and Morbidity for 1999.

\section{Materials and methods}

JSACORS sent confidential questionnaires to all JSACTHs at the end of 1999 and collected the completed questionnaires by the end of March 2000. The questionnaires were collected by mail in a double envelope to protect the confidential data of the hospitals and to encourage precise responses to the questionnaire. The name of the hospital was printed only on the outer envelope, and this envelope was discarded immediately after the name of the responding hospital was checked on a list. A secretary of the JSA pulled the questionnaire document from the inner envelope, which did not identify the hospital. To avoid exposure of the confidential data to a third party in case the envelope was accidentally opened, only the code and number were recorded on the answer sheet.

The hospitals were requested to report all cases of cardiac arrest and other critical incidents and their outcomes (death in the operating room, death within 7 days after surgery, survival in vegetative state, and rescue without sequelae). Other critical incidents included serious hypotension, hypoxemia, and other events that suggested impending cardiac arrest or postoperative cerebral and/or myocardial damage. They were also requested to choose one principal cause for each incident from a list of 52 items classified into four categories: totally attributable to anesthetic management (AM), due mainly to intraoperative pathological events (IP), due mainly to preoperative complications (PC), and 
due mainly to surgery (SG) (Table 1 ). The representative board-certified anesthesiologist in each hospital was responsible for inspecting the records of all anesthesias performed in the hospital, analyzing them, filling the questionnaires, and then sending the leaflet with the summarized data to the JSA office.

Further, they were requested to submit the total number of anesthesias as well as to tabulate anesthesias according to ASA-PS, age distribution, surgical site, and anesthetic method for analysis of detailed incidences. Critical incidents reported without tabulation of anesthesias by ASA-PS, age distribution, surgical site, or anesthetic method from that hospital were excluded from the calculation. ASA-PS was classified from 1 to 6 in both elective and emergency cases. Patients were classified into seven age groups: newborn (under 1 month), infant (1-12 months), 1-5 years, 6-18 years, 1965 years, $66-85$ years, and 86 or more years. Surgical sites were classified as craniotomy, thoracotomy, heart and great vessels, thoracotomy with laparotomy, laparotomy, cesarean section, head-neck-ENT, chestabdomen-perineum, spine, extremities including peripheral vessels, and others. Anesthetic methods were classified as inhalation, total intravenous anesthesia (TIVA), inhalation with neuraxial or conduction block, TIVA with neuraxial or conduction block, combined spinal epidural anesthesia, (CSEA), epidural block, spinal block, conduction block, and others.

Neither the commissioner nor the members of JSACORS could ask further questions about the reported answers, and all raw data were used for the statistical analysis. The members of JSACORS sorted and analyzed documented data on patients as a whole and also with special reference to ASA-PS, age distribu- tion, surgical site, and anesthetic method. Incidences of cardiac arrest and other critical incidents and their outcomes were calculated by the total number incidents under anesthesia and surgery and also by four major categories of incidents (AM, IP, PC, and SG). Statistical analysis was performed by the $\chi^{2}$ test. $P$ values less than 0.05 were considered to be significant.

Four hundred sixty-seven CTHs out of 774 (60.3\%) responded to the questionnaires, and a total of 793847 anesthesias were documented in 1999.The types of hospital that responded included university hospitals, national centers and hospitals, prefectural and municipal hospitals, other general hospitals, and children's medical centers and hospitals. Responses were received from hospitals in all 47 prefectures in Japan.

\section{Analysis of all patients}

Table 1 summarizes cardiac arrest, other critical incidents, and their outcomes in relation to 52 detailed principal causes under four major categories. The incidence of total cardiac arrest from any cause in 793847 anesthesias was 6.53 per 10000 . The incidence of cardiac arrest due to AM, IP, PC, and SG was $0.78,1.44$, 2.80, and 1.40 per 10000 , respectively (Fig. 1). The five major causes of cardiac arrest were preoperative hemorrhagic shock (20.3\%), massive hemorrhage due to surgery $(13.1 \%)$, intraoperative onset of myocardial infarction or coronary ischemia $(9.5 \%)$, preoperative complications of myocardial infarction or coronary ischemia $(6.8 \%)$, and surgery itself $(6.8 \%)$. The top ten causes of cardiac arrest did not include any cause categonized as AM. The incidence of total critical

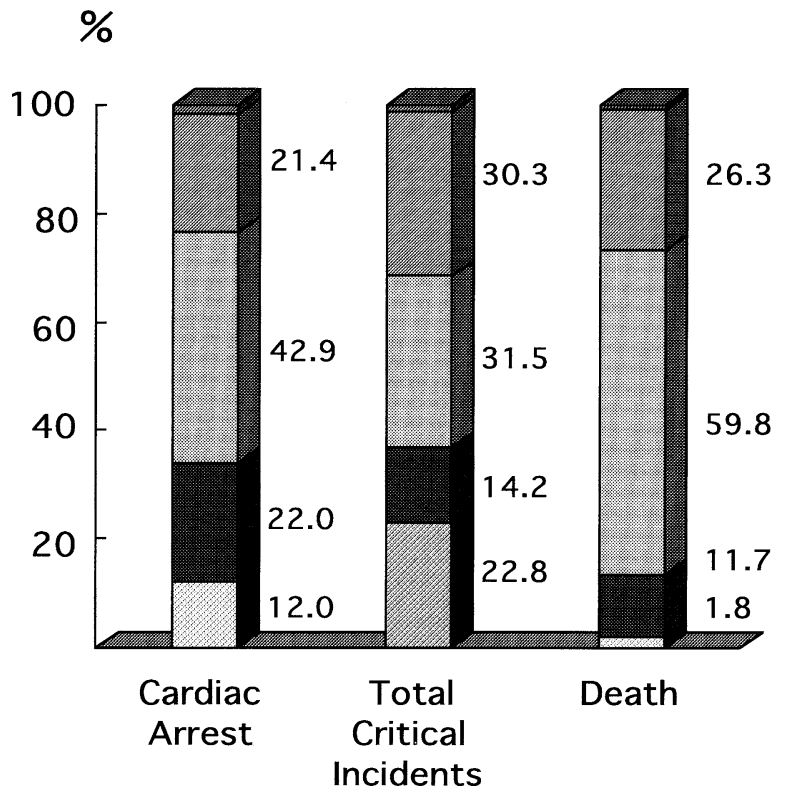

\section{Others}

Surgery

Preoperative Complication

- Intraoperative Pathological Event

$\checkmark$ Anesthetic Management
Fig. 1. Contribution of the four major categories of principal causes of cardiac arrest, total critical incidents, and deaths $(n=793847)$ 
Table 1. Distribution of total critical incidents and their outcomes by 52 principal causes in $1999(n=793847)$

\begin{tabular}{|c|c|c|c|c|c|c|}
\hline \multirow[b]{2}{*}{ Principal cause } & \multicolumn{2}{|c|}{ Critical incident } & \multicolumn{3}{|c|}{ Outcome $(\%)^{a}$} & \multirow[b]{2}{*}{ Other } \\
\hline & $\begin{array}{l}\text { Cardiac } \\
\text { arrest }\end{array}$ & $\begin{array}{c}\text { Other } \\
\text { critical } \\
\text { incident }^{\mathrm{b}}\end{array}$ & $\begin{array}{c}\text { Uneventful } \\
\text { recovery }\end{array}$ & Death $^{c}$ & $\begin{array}{c}\text { Vegetative } \\
\text { state }\end{array}$ & \\
\hline \multicolumn{7}{|l|}{ Totally attributable to anesthetic management } \\
\hline \multicolumn{7}{|l|}{ Human factor } \\
\hline Inadequate vigilance & 9 & 17 & 92.3 & & 3.8 & 3.8 \\
\hline Overdose of main anesthetics & 3 & 72 & 97.3 & 2.7 & & \\
\hline Inadvertent high spinal anesthesia & 6 & 20 & 92.3 & 7.7 & & \\
\hline Local anesthetics intoxication & 2 & 17 & 89.5 & 5.3 & & 5.3 \\
\hline Drug overdose or selection error & 6 & 97 & 96.1 & & & 3.9 \\
\hline Swap drug ampule/syringe & 2 & 11 & 100.0 & & & \\
\hline \multicolumn{7}{|l|}{ Gas flow setting error } \\
\hline Hypoventilation (human error) & 5 & 24 & 89.7 & 3.4 & & 6.9 \\
\hline Inappropriate airway management & 7 & 130 & 94.9 & & 0.7 & 4.4 \\
\hline Suffocation, aspiration & 1 & 24 & 96.0 & & & 4.0 \\
\hline Pneumothorax, pneumomediastinum & & 7 & 85.7 & & & 14.3 \\
\hline Incompatible blood transfusion & & 2 & 50.0 & 50.0 & & \\
\hline Inappropriate infusion, transfusion & 7 & 26 & 93.9 & & & 6.1 \\
\hline Others & 9 & 51 & 80.0 & 1.7 & & 18.3 \\
\hline \multicolumn{7}{|l|}{ Disconnection, misconnection } \\
\hline Breathing circuit & 3 & 11 & 85.7 & 7.1 & & 7.1 \\
\hline Loss of gas supply & & 2 & 50.0 & & & 50.0 \\
\hline Arterial/venous line & & 2 & 100.0 & & & \\
\hline Others & & 2 & 50.0 & & & 50.0 \\
\hline \multicolumn{7}{|l|}{ Equipment failure } \\
\hline Anesthesia machine & & 2 & 100.0 & & & \\
\hline \multicolumn{7}{|l|}{ Ventilator } \\
\hline Breathing circuit & & 3 & 100.0 & & & \\
\hline Airway devices & & 7 & 100.0 & & & \\
\hline Monitoring & & & & & & \\
\hline Laser machine & & & & & & \\
\hline Macro/microshock & 1 & 1 & 100.0 & & & \\
\hline Others & 1 & 5 & 66.7 & 16.7 & & 16.7 \\
\hline Subtotal & 62 & 533 & 92.4 & 1.7 & 0.3 & 5.5 \\
\hline Intraoperative pathological events & & & & & & \\
\hline Myocardial infarction, ischemia, coronary spasm & 49 & 68 & 69.2 & 26.5 & & 4.3 \\
\hline Serious arrhythmia & 30 & 29 & 81.4 & 10.2 & & 8.5 \\
\hline Pulmonary embolism & 21 & 33 & 38.9 & 37.0 & 9.3 & 14.8 \\
\hline Asthmatic attack & 1 & 33 & 97.1 & 2.9 & & \\
\hline CNS derangement & & 6 & 16.7 & 33.3 & & 50.0 \\
\hline Anaphylactic shock & 2 & 37 & 82.1 & & & 17.9 \\
\hline Malignant hyperthermia & 1 & 4 & 100.0 & & & \\
\hline Others & 10 & 46 & 85.7 & 12.5 & & 1.8 \\
\hline Subtotal & 114 & 256 & 72.7 & 18.1 & 1.4 & 7.8 \\
\hline Preoperative complications & & & & & & \\
\hline Cardiovascular events & & & & & & \\
\hline Myocardial infarction, ischemia & 35 & 49 & 48.8 & 41.7 & & 9.5 \\
\hline Valvular disease & 1 & 11 & 66.7 & 25.0 & 8.3 & \\
\hline Cardiomyopathy & 2 & 4 & 66.7 & 33.3 & & \\
\hline Cardiac failure & 10 & 44 & 64.8 & 31.5 & 1.9 & 1.9 \\
\hline Hemorrhagic shock & 105 & 173 & 24.5 & 67.3 & 0.4 & 7.9 \\
\hline Congenital heart disease & 18 & 24 & 50.0 & 45.2 & & 4.8 \\
\hline Others & 19 & 65 & 61.9 & 29.8 & & 8.3 \\
\hline Respiratory & 7 & 100 & 82.2 & 11.2 & & 6.5 \\
\hline CNS derangement & & & & & & \\
\hline Subarachnoid hemorrhage & 1 & 13 & 21.4 & 21.4 & 35.7 & 21.4 \\
\hline Others & 9 & 23 & 28.1 & 37.5 & 15.6 & 18.8 \\
\hline MODS, sepsis & 3 & 6 & 11.1 & 77.8 & & 11.1 \\
\hline Endocrine disease & 5 & 25 & 73.3 & 16.7 & 3.3 & 6.7 \\
\hline Musculoskeletal & 1 & 5 & 83.3 & 16.7 & & \\
\hline Others & 6 & 58 & 67.2 & 20.3 & & 12.5 \\
\hline Subtotal & 222 & 600 & 48.7 & 41.5 & 1.7 & 8.2 \\
\hline Surgery & & & & & & \\
\hline Surgery & 35 & 174 & 78.5 & 12.9 & 0.5 & 8.1 \\
\hline Massive hemorrhage, hypovolemia & 68 & 476 & 72.6 & 21.9 & 0.4 & 5.1 \\
\hline Others & 8 & 31 & 74.4 & 10.3 & & 15.4 \\
\hline Subtotal & 111 & 681 & 74.2 & 18.9 & 0.4 & 6.4 \\
\hline Others & 9 & 22 & 64.5 & 9.7 & & 25.8 \\
\hline Total & 518 & 2092 & 70.0 & 21.9 & 0.9 & 7.2 \\
\hline
\end{tabular}

MODS, multiple organ dysfunction syndrome

${ }^{a}$ Outcomes were expressed as percentage of each principal cause in total critical incidents (cardiac arrest plus other incidents)

${ }^{\mathrm{b}}$ Including serious hypotension, serious hypoxemia, and others

${ }^{c}$ Including death in the operating room and death within seven postoperative days 


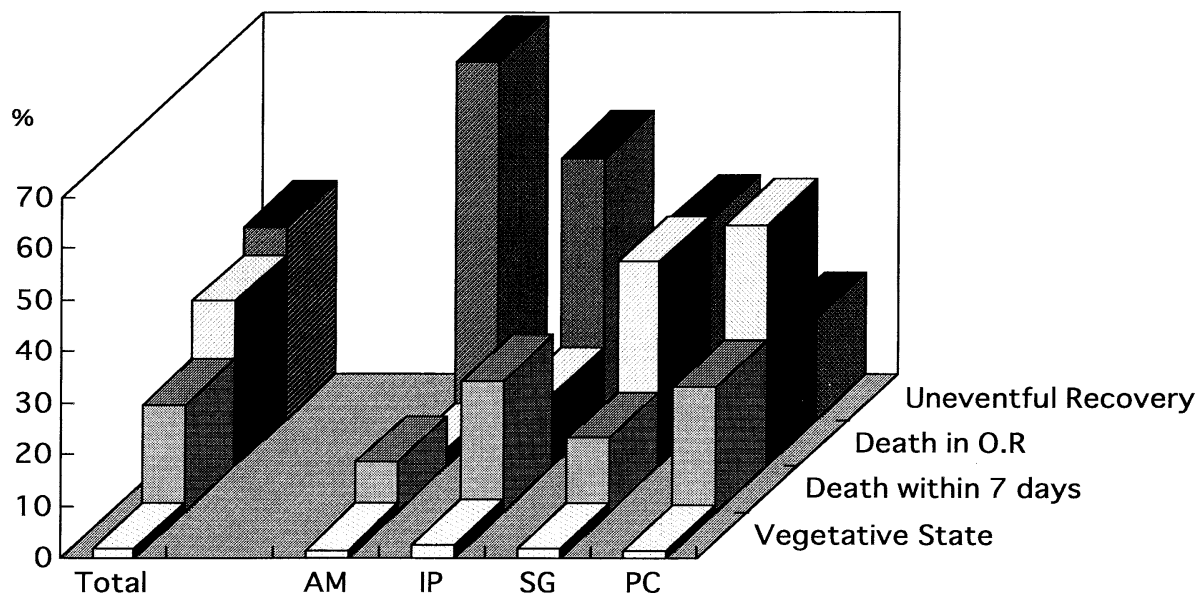

Fig. 2. Outcomes of total cardiac arrest according to the four major categories of principal causes of incidents $(n=793847)$. AM, Anesthetic management; $I P$, intraoperative pathological events; $S G$, surgery; $P C$, preoperative complication; Total, total of these four categories. A small number of outcomes with other causes not included in these four categories are omitted. $P<0.01$ between AM, IP, SG, and PC as to outcomes of cardiac arrest $\left(\chi^{2} m \times n\right.$ test) incidents due to any cause, including cardiac arrest, was 32.38 per 10000 anesthesias.

Among patients with total cardiac arrest, $32.0 \%$ died in the operating room, $20.7 \%$ died within 7 days after surgery, $1.7 \%$ survived in a vegetative state, and only $37.5 \%$ were rescued without any sequelae. Patients with cardiac arrest due to PC had a worse outcome than those with cardiac arrest due to AM, IP, or SG (Fig. 2). Among patients in this group, $46.8 \%$ died in the operating room, $24.3 \%$ died within 7 days after surgery, and only $19.8 \%$ survived without sequelae. Those with cardiac arrest due to AM had the best prognosis, with $69.4 \%$ surviving without sequelae and $12.9 \%$ dying.

The mortality rate after cardiac arrest from any cause was 3.44 per 10000 anesthesias: 0.10 due to AM, 0.57 to IP, 1.99 to PC, and 0.76 to SG. The mortality rate after critical incidents other than cardiac arrest, such as severe hypotension and hypoxemia, was 3.75: 0.03 due to AM, 0.28 to IP, 2.31 to PC, and 1.13 to SG. The final mortality rate from any cause, including deaths after cardiac arrest and after other critical incidents, was 7.19 per 10000 anesthesias: 0.13 attributable to AM and 0.84 , 4.30, and 1.89 to IP, PC, and SG, respectively (Fig. 1). Table 2 lists 13 patients who died in the operating room or within 7 days after surgery or who survived in a vegetative state according to the principal causes totally attributable to AM.

A series of reports of anesthesia-related mortality and morbidity in JSACTHs from 1994 to 1998 has been published elsewhere in Japanese without English abstracts [1-6]. Table 3 summarizes the incidences of cardiac arrest and total critical incidents and mortality rates in 1994-1998 and in 1999. The total mortality and morbidity due to any cause in 1999 were quite similar to the average values in 1994-1998 [6], whereas those due to anesthetic management improved slightly in 1999. National studies of anesthetic mortality and morbidity, at least at the state level, are very limited, and the definitions of death are variable. However, the incidences of cardiac arrest and death totally attributable to AM in Japan were comparable to those previously reported in France [13], three NHS regions of the United Kingdom [14], New South Wales in Australia [15-17], and Finland [18]. JSACORS started the new survey in 1999 to tabulate the principal causes of cardiac arrest and other critical incidents in four major categories. The incidences of cardiac arrest, death after cardiac arrest, and death after other critical incidents were worst when these events were caused by PC, followed by IP, then SG. Those incidences were best when the event was caused by AM. Further, the outcomes of cardiac arrest and other critical incidents were worst when the event was caused by PC and best when it was caused by AM (Fig. 2). The percentages of patients with uneventful recovery from cardiac arrest due to PC and that totally attributable to AM were 19.8 and 69.4, respectively. Similarly, Tikkannen and Hovi-Viander [18] reported that $95.3 \%$ of anesthesia-related deaths occurred mainly as a result of disease, $3.9 \%$ were caused by surgery, and only $0.9 \%$ were caused by anesthesia.

\section{Analysis according to ASA-PS}

The number of anesthesias we could analyze according to ASA-PS was 655644 from 502 JSACTHs, $82.6 \%$ of the total anesthesias documented in 1999. Table 4 summarizes the number of anesthesias, critical incidents, and their outcomes as to ASA-PS. ASA-PS 1, 2, 1E, and $2 \mathrm{E}$ accounted for $86.0 \%$. Table 5 summarizes the incidences of cardiac arrest and total critical incidents per 10000 anesthesias, including serious hypotension, hypoxemia, and others, for the four major categories of principal causes according to ASA-PS. Figure 3 shows the mortality rate (death during anesthesia and within 7 days after surgery) due to any cause and that totally attributable to AM according to ASA-PS.

The final mortality rates (death during anesthesia or within seven postoperative days) from all critical 


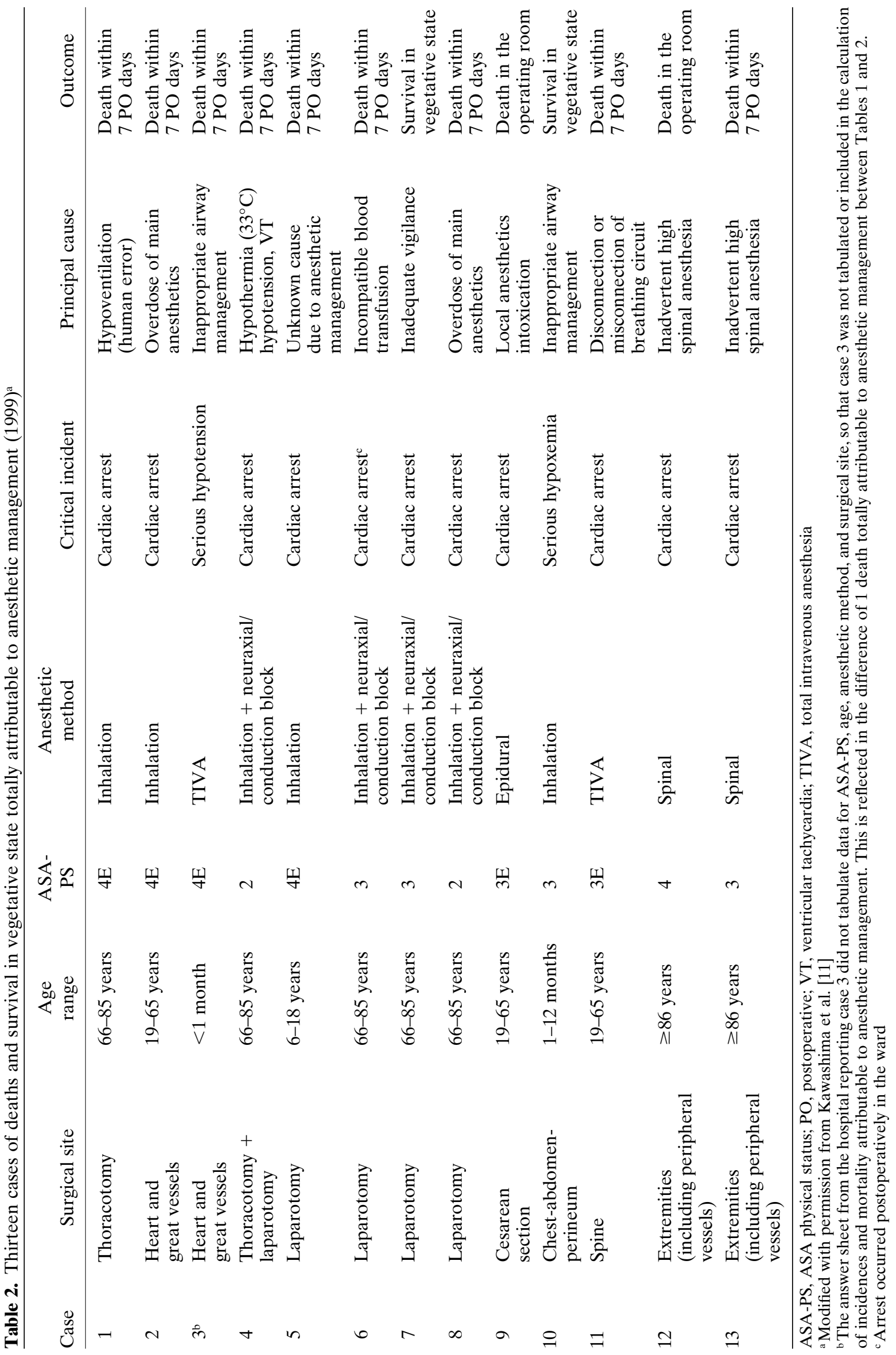


Table 3. Comparison of incidences and mortality in 1994-1998 and in 1999

\begin{tabular}{|c|c|c|c|c|c|c|}
\hline \multirow[b]{2}{*}{ Cause } & \multicolumn{2}{|c|}{ Incidence of cardiac arrest } & \multicolumn{2}{|c|}{ Total critical incidents } & \multicolumn{2}{|c|}{ Total mortality } \\
\hline & 1994-1998a & $1999^{\mathrm{b}}$ & 1994-1998a & $1999^{b}$ & $1994-1998^{a}$ & $1999^{b}$ \\
\hline Total & $7.12[6.30,7.94]$ & 6.53 & $42.31[34.59,50.02]$ & 32.38 & $7.18[6.22,8.13]$ & 7.19 \\
\hline $\mathrm{AM}$ & $1.00[0.88,1.12]$ & 0.78 & $12.85[10.54,15.17]$ & 7.50 & $0.21[0.15,0.27]$ & 0.13 \\
\hline IP & - & 1.44 & - & 4.66 & - & 0.84 \\
\hline $\mathrm{PC}$ & - & 2.80 & - & 10.35 & - & 4.30 \\
\hline SG & - & 1.40 & - & 9.98 & - & 1.89 \\
\hline
\end{tabular}

AM, Anesthetic management; IP, intraoperative pathological event; PC, preoperative complication; SG, surgery

${ }^{a} n=2363038$. Data are expressed as mean [95\% CI]

${ }^{\mathrm{b}} n=793847$

Table 4. Critical incidents and their outcomes according to ASA-PS (1999)a

\begin{tabular}{|c|c|c|c|c|c|c|c|c|}
\hline \multirow[b]{2}{*}{ ASA-PS } & \multirow[b]{2}{*}{$n$} & \multirow[b]{2}{*}{$\%$} & \multicolumn{2}{|c|}{ Critical incident } & \multicolumn{4}{|c|}{ Outcome $(\%)^{\mathrm{b}}$} \\
\hline & & & $\begin{array}{l}\text { Cardiac } \\
\text { arrest }\end{array}$ & $\begin{array}{l}\text { Other critical } \\
\text { incidents }\end{array}$ & $\begin{array}{l}\text { Uneventful } \\
\text { recovery }\end{array}$ & Death $^{\mathrm{d}}$ & $\begin{array}{c}\text { Vegetative } \\
\text { state }\end{array}$ & Others \\
\hline 1 & 249765 & 36.1 & 17 & 206 & 94.6 & 2.7 & 0.0 & 2.7 \\
\hline 2 & 265691 & 40.5 & 100 & 617 & 87.9 & 6.1 & 0.6 & 5.4 \\
\hline 3 & 54279 & 8.3 & 78 & 309 & 71.1 & 17.1 & 1.3 & 10.6 \\
\hline 4 & 2387 & 0.4 & 16 & 29 & 53.3 & 35.6 & 2.2 & 8.9 \\
\hline 5 & 134 & 0.02 & 0 & 1 & 100.0 & 0.0 & 0.0 & 0.0 \\
\hline 6 & 10 & 0.002 & 0 & 0 & 0.0 & 0.0 & 0.0 & 0.0 \\
\hline Subtotal & 572266 & 87.3 & 211 & 1162 & 83.1 & 9.6 & 0.7 & 6.6 \\
\hline $1 \mathrm{E}$ & 27648 & 4.2 & 1 & 23 & 95.8 & 0.0 & 0.0 & 4.2 \\
\hline $2 \mathrm{E}$ & 34223 & 5.2 & 16 & 91 & 82.2 & 11.2 & 0.0 & 6.5 \\
\hline $3 E$ & 16451 & 2.5 & 46 & 178 & 59.8 & 25.4 & 1.8 & 12.9 \\
\hline $4 \mathrm{E}$ & 4411 & 0.7 & 91 & 227 & 28.6 & 57.9 & 1.9 & 11.6 \\
\hline $5 \mathrm{E}$ & 629 & 0.1 & 79 & 46 & 10.4 & 82.4 & 1.6 & 5.6 \\
\hline $6 \mathrm{E}$ & 16 & 0.02 & 2 & 1 & 0.0 & 100.0 & 0.0 & 0.0 \\
\hline Subtotal & 83378 & 12.7 & 235 & 566 & 43.6 & 44.8 & 1.5 & 10.1 \\
\hline Total & 655647 & 100.0 & 446 & 1728 & 68.5 & 22.6 & 1.0 & 7.9 \\
\hline
\end{tabular}

PS, Physical status; E, emergency surgery

${ }^{a}$ Modified with permission from Irita et al. [7]

${ }^{\mathrm{b}}$ Outcomes are expressed as percentages of patients with each ASA-PS

${ }^{c}$ Including serious hypotension, serious hypoxemia, and others

${ }^{\mathrm{d}}$ Including death in the operating room and death within seven postoperative days

incidents due to any cause in our study were well correlated with ASA-PS and were higher for emergency anesthesias than for elective anesthesias (Fig. 3A). Patients with ASA-PS of 4E and 5E had strikingly high mortality rates. Our results with regard to ASA-PS were very close to those reported previously. Tiret et al. [13] and Tikkannen and Hovi-Viander [18] demonstrated that increasing ASA-PS was associated with increasing mortality. Olsson and Hallen [19] in Sweden and Biboulet et al. [20] in France also reported that increasing ASA-PS was associated with an increasing incidence of cardiac arrest. Using a multiple logistic regression model, Cohen et al. [21] demonstrated that both increasing PS and emergency procedures were determinants of the independent predictors of mortality.

With regard to the risk of emergency surgery, however, the results were controversial. Tiret et al. [13] reported that emergency surgery increased the risk dramatically in patients with ASA-PS 4 and 5. Keenan and Boyan [22] reported a six-times higher incidence of cardiac arrest in emergency cases. On the other hand, Olsson and Hallen [19] and Biboulet et al. [20] found no difference in those incidences between elective and emergency cases. The reason for this discrepancy is not clear at present.

The mortality rate totally attributable to AM was also well correlated with ASA-PS in our study and was high in patients with ASA-PS 3E and 4E (Fig. 3B). All patients with $\mathrm{PS}$ of $5 \mathrm{E}$ or $6 \mathrm{E}$ died of one of the principal causes in the PC, SG, and IP categories. Among patients with good PS of 1, 2, 1E, and 2E, only one death totally attributable to AM, which was due to an overdose of the main anesthetics, was reported (Table 2). The mortality totally attributable to AM among 577322 patients in 
Table 5. Incidences of cardiac arrest and total critical incidents according to ASA-PS and four major categories of principal cause $(1999)^{\mathrm{a}}$

\begin{tabular}{|c|c|c|c|c|c|c|c|c|c|c|}
\hline \multirow[b]{2}{*}{ ASA-PS } & \multicolumn{5}{|c|}{ Cardiac arrest } & \multicolumn{5}{|c|}{ Total critical incidents } \\
\hline & AM & IP & $\mathrm{PC}$ & SG & Total & $\mathrm{AM}$ & IP & $\mathrm{PC}$ & SG & Total \\
\hline 1 & 0.24 & 0.20 & 0.00 & 0.20 & 0.68 & 4.92 & 1.08 & 0.40 & 2.32 & 8.93 \\
\hline 2 & 0.45 & 1.73 & 0.38 & 1.13 & 3.76 & 8.81 & 6.13 & 3.27 & 8.32 & 26.99 \\
\hline 3 & 1.47 & 4.42 & 4.24 & 4.05 & 14.37 & 14.74 & 14.37 & 19.16 & 22.66 & 71.30 \\
\hline 4 & 8.38 & 16.76 & 33.51 & 8.38 & 67.03 & 20.95 & 20.95 & 125.68 & 20.95 & 188.52 \\
\hline 5 & 0.00 & 0.00 & 0.00 & 0.00 & 0.00 & 0.00 & 0.00 & 74.63 & 0.00 & 74.63 \\
\hline 6 & 0.00 & 0.00 & 0.00 & 0.00 & 0.00 & 0.00 & 0.00 & 0.00 & 0.00 & 0.00 \\
\hline Subtotal & 0.49 & 1.38 & 0.72 & 1.03 & 3.69 & 7.72 & 4.77 & 4.05 & 7.11 & 23.99 \\
\hline $1 \mathrm{E}$ & 0.36 & 0.00 & 0.00 & 0.00 & 0.36 & 4.34 & 2.17 & 1.45 & 0.36 & 8.68 \\
\hline $2 \mathrm{E}$ & 1.75 & 1.46 & 0.29 & 1.17 & 4.68 & 11.40 & 6.43 & 7.01 & 6.14 & 31.27 \\
\hline $3 E$ & 2.43 & 6.08 & 12.16 & 7.29 & 27.96 & 15.80 & 10.33 & 79.02 & 30.39 & 136.16 \\
\hline $4 \mathrm{E}$ & 11.34 & 9.07 & 156.43 & 29.47 & 206.30 & 22.67 & 31.74 & 80.80 & 81.61 & 720.92 \\
\hline $5 \mathrm{E}$ & 0.00 & 0.00 & 1128.78 & 127.19 & 1255.96 & 0.00 & 15.90 & 1780.60 & 190.78 & 1987.28 \\
\hline $6 \mathrm{E}$ & 0.00 & 625.00 & 625.00 & 0.00 & 1250.00 & 0.00 & 625.00 & 625.00 & 625.00 & 1875.00 \\
\hline Subtotal & 1.92 & 2.40 & 19.43 & 4.44 & 28.18 & 10.43 & 7.32 & 63.33 & 14.51 & 96.07 \\
\hline Total & 0.67 & 1.51 & 3.10 & 1.46 & 6.80 & 8.07 & 5.09 & 11.59 & 8.05 & 33.16 \\
\hline
\end{tabular}

Modified with permission from Irita et al. [7]

AM, Anesthetic management; IP, intraoperative pathological event; PC, preoperative complication; SG, surgery; E, emergency

a The total number of anesthesias was 655644 . Incidences are expressed per 10000 anesthesias

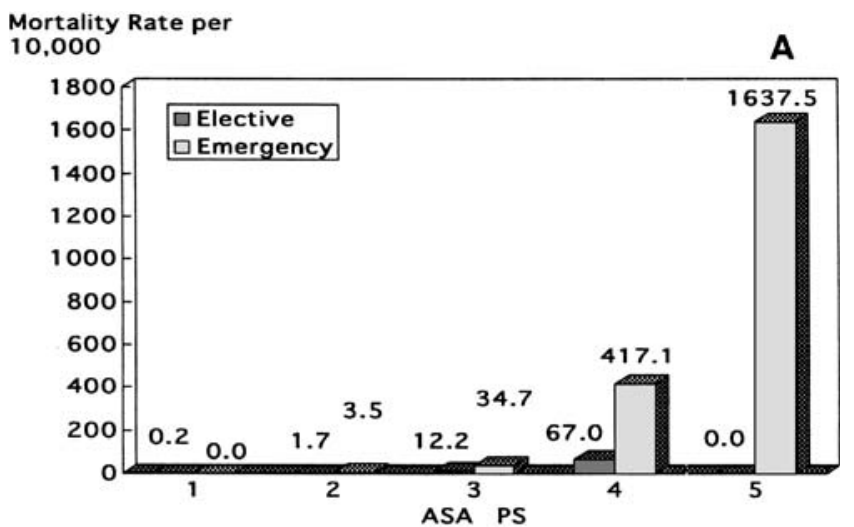

Mortality Rate per

10,000Anesthetic

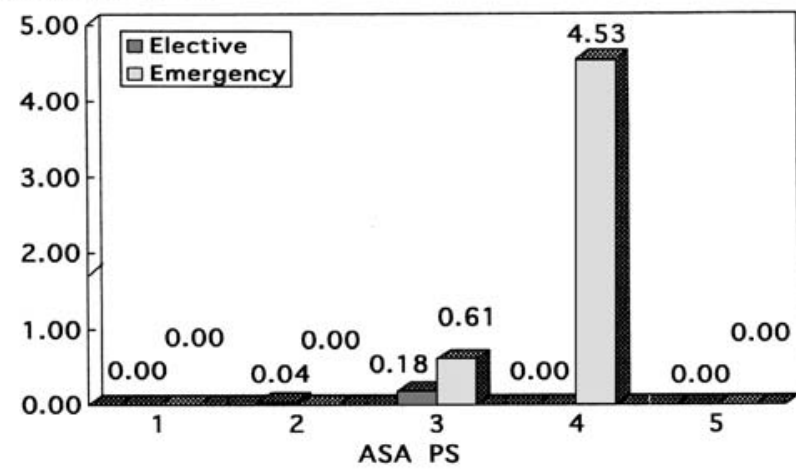

Fig. 3A,B. Mortality rate according to ASA physical status $(A S A P S)$ in elective and emergency surgery. A Mortality due to all etiology, $\mathbf{B}$ mortality totally attributable to anesthetic management $(n=655644)$. (Modified with permission from Irita et al. [7]) these ASA-PS groups was 1.7 per 1 million, which attained the so-called 6 sigma level. We reconfirmed that ASA-PS is a highly powerful predictor of preoperative mortality and morbidity.

AM was mainly responsible for cardiac arrest and other critical incidents in patients with good ASA-PS, whereas PC was mainly responsible in those with poor ASA-PS in this study. The major preoperative complications or conditions leading to critical events were ischemic heart disease in elective cases and hemorrhagic shock in emergency cases.

\section{Analysis according to age group}

The number of anesthesias we could analyze according to age group was 732788 from 514 JSACTHs, which was $92.3 \%$ of the total anesthesias documented in 1999. Table 6 summarizes the number of anesthesias, critical incidents, and their outcomes according to age group. Table 7 summarizes the incidences of cardiac arrest and total critical incidents according to age group and the four major categories of principal causes. The incidences of cardiac arrest and all critical incidents from any cause were much higher in newborns than in any other age group. The mortality rates after cardiac arrest from any cause were 42.75, 2.95, 2.54, 1.70, 2.00, 6.56, and 5.18 in patients aged less than 1 month, 1-12 months, $1-5$ years, $6-18$ years, $19-65$ years, $66-85$ years, and 86 or more years, respectively. The mortality rates after cardiac arrest and after all critical incidents (Fig. 4A) were highest in newborns. The mortality rate of 
Table 6. Critical incidents and their outcomes according to age group (1999) ${ }^{\mathrm{a}}$

\begin{tabular}{|c|c|c|c|c|c|c|c|c|}
\hline \multirow[b]{2}{*}{ Age group } & \multirow[b]{2}{*}{$n$} & \multirow[b]{2}{*}{$\%$} & \multicolumn{2}{|c|}{ Critical incident } & \multicolumn{4}{|c|}{ Outcome $(\%)^{\mathrm{b}}$} \\
\hline & & & $\begin{array}{c}\text { Cardiac } \\
\text { arrest }\end{array}$ & $\begin{array}{l}\text { Other critical } \\
\text { incidents }\end{array}$ & $\begin{array}{l}\text { Uneventful } \\
\text { recovery }\end{array}$ & Death $^{\mathrm{d}}$ & $\begin{array}{l}\text { Vegetative } \\
\text { state }\end{array}$ & Others \\
\hline$<1$ month & 3509 & 0.5 & 19 & 40 & 49.2 & 44.1 & 0.0 & 6.8 \\
\hline $1-12$ months & 13580 & 1.9 & 12 & 53 & 78.5 & 13.8 & 3.1 & 4.6 \\
\hline $1-5$ years & 39380 & 5.4 & 20 & 77 & 77.3 & 13.4 & 0.0 & 9.3 \\
\hline $6-18$ years & 58700 & 8.0 & 15 & 71 & 75.6 & 20.9 & 0.0 & 3.5 \\
\hline 19-65 years & 409051 & 55.8 & 198 & 965 & 75.2 & 16.9 & 0.9 & 6.9 \\
\hline $66-85$ years & 195060 & 26.6 & 215 & 765 & 64.2 & 27.3 & 1.0 & 7.4 \\
\hline$>86$ years & 13508 & 1.8 & 9 & 50 & 59.3 & 27.1 & 0.0 & 13.6 \\
\hline Total & 732788 & 100.0 & 488 & 2021 & 70.1 & 21.8 & 0.9 & 7.2 \\
\hline
\end{tabular}

${ }^{a}$ Modified with permission from Morita et al. [8]

${ }^{b}$ Outcomes are expressed as percentages of patients in each age group

${ }^{\mathrm{c}}$ Including serious hypotension, serious hypoxemia, and others

${ }^{\mathrm{d}}$ Including death in the operating room and death within seven postoperative days

Table 7. Incidence of cardiac arrest and total critical incidents according to age group and four major categories of principal cause $(1999)^{\mathrm{a}}$

\begin{tabular}{|c|c|c|c|c|c|c|c|c|c|c|}
\hline \multirow[b]{2}{*}{ Age group } & \multicolumn{5}{|c|}{ Cardiac arrest } & \multicolumn{5}{|c|}{ Total critical incidents } \\
\hline & $\mathrm{AM}$ & IP & $\mathrm{PC}$ & SG & Total & AM & IP & $\mathrm{PC}$ & SG & Total \\
\hline$<1$ month & 0.00 & 2.85 & 31.35 & 19.95 & 54.15 & 31.35 & 8.55 & 94.04 & 34.20 & 168.14 \\
\hline $1-12$ months & 1.47 & 0.74 & 4.42 & 2.21 & 8.84 & 16.94 & 3.68 & 15.46 & 11.05 & 47.86 \\
\hline $1-5$ years & 0.25 & 0.25 & 3.30 & 1.02 & 5.08 & 6.35 & 4.57 & 7.87 & 5.33 & 24.63 \\
\hline $6-18$ years & 0.34 & 0.00 & 1.53 & 0.68 & 2.56 & 4.60 & 2.04 & 6.13 & 1.70 & 14.65 \\
\hline 19-65 years & 0.83 & 1.37 & 1.64 & 0.90 & 4.84 & 6.09 & 3.86 & 7.26 & 10.90 & 28.43 \\
\hline $66-85$ years & 0.92 & 2.41 & 4.92 & 2.56 & 11.02 & 10.77 & 7.84 & 17.38 & 13.53 & 50.24 \\
\hline$>86$ years & 2.22 & 0.74 & 2.22 & 1.48 & 6.66 & 14.07 & 3.70 & 16.29 & 9.62 & 43.68 \\
\hline Total & 0.82 & 1.46 & 2.80 & 1.46 & 6.66 & 7.70 & 4.83 & 10.63 & 10.66 & 34.24 \\
\hline
\end{tabular}

Modified with permission from Morita et al. [8]

AM, Anesthetic management; IP, intraoperative pathological event; PC, preoperative complication; SG, surgery

a The total number of anesthesias was 732788 . Incidences are expressed per 10000 anesthesias

74.10 in newborns actually corresponded to 26 deaths out of 3509 anesthesias, of which 21 were due to PC and 5 to SG. Seventeen of 21 deaths were due to cardiovascular complications, including 11 from congenital heart disease. Because PC and SG were the principal causes of death, and no death totally attributable to AM was recorded, it is suggested that the prognosis depended on the pathology of congenital heart disease in this age group. The mortality rate attributable to AM was very low in general, and no death occurred among newborns, infants, or children 1-5 years of age (Fig. 4B), but the rate was highest in the group over 86 years of age.

Cohen et al. [21] reported that the odds of dying within 7 days of surgery among patients over 80 years of age relative to those below 60 years of age was 3.29. We obtained comparable results in the present study. The rates of mortality due to any cause in patients aged 1965 years, $66-85$ years, and over 86 years were $4.82,13.74$, and 11.84 per 10000 anesthesias, respectively. The principal causes of death or transfer to vegetative state in aged patients were IP, such as myocardial infarction or pulmonary embolism. The rate of mortality from AM of
1.48 in patients over 86 years of age was the highest of all age groups (Fig. 4B), and was due to two deaths in 13500 cases. These two patients had ASA-PS 3E and 4E and died of inadvertent high spinal anesthesia for extremity surgery.

Age-group classifications varied among studies. However, patients at both ends of the age distribution, that is, newborns and infants under 1 year of age and aged patients, had the highest incidences of cardiac arrest and mortality $[5,14,19,20]$. Among the patients who had a critical incident in our study, $44.1 \%$ of newborns and $32.0 \%$ of those over 86 years of age died within seven postoperative days. After cardiac arrest, $80.8 \%$ of newborns and $88.8 \%$ of those over 86 years of age died. These data indicate that resuscitation in these two groups is exceptionally difficult once cardiac arrest has occurred.

\section{Analysis according to surgical site}

The number of anesthesias that we could analyze according to surgical site was 701090 from 516 JSACTHs, 


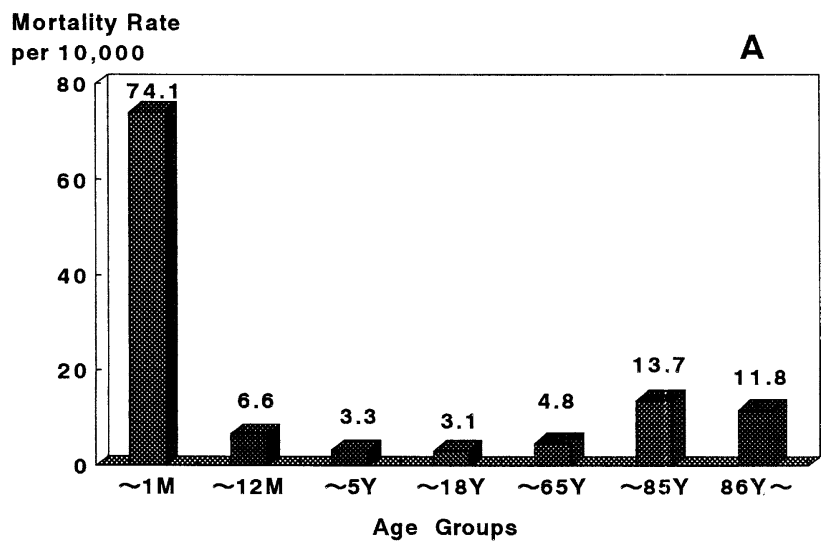

Mortality Rate per

10,000 Anesthetics

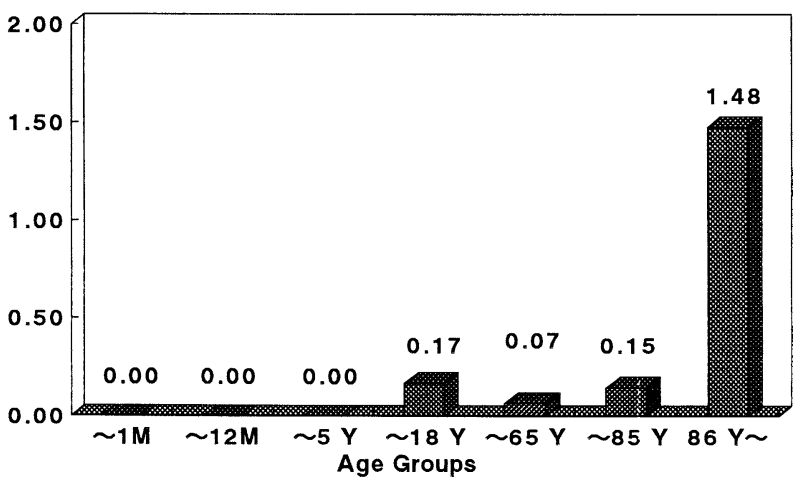

Fig. 4A,B. Mortality rate according to age group. A Mortality from any cuase. B Mortality totally attributable to anesthetic management $(n=732788)$. (Modified with permission from Morita et al. [8])
$88.4 \%$ of the total anesthetics documented in 1999. Table 8 summarizes the number of anesthesias, critical incidents, and their outcomes according to surgical site. The incidence of cardiac arrest from any cause was highest during surgery of the heart and great vessels, thoracotomy with laparotomy, thoracotomy, craniotomy, and laparotomy (Table 9). Mortality rates after cardiac arrest at these surgical sites, except for thoracotomy, exceeded $50 \%$. The incidences of all critical events from any cause were highest during surgery on the heart and great vessels, followed by thoracotomy with laparotomy, thoracotomy, craniotomy, and laparotomy. Overall mortality was also highest for these five surgical sites (Fig. 5A). Laparotomy, the most frequent type of surgery, was associated with overall mortality of 6.8 per 10000 anesthesias. Mortality was higher for craniotomy and thoracotomy than for laparotomy. Cardiovascular surgery and thoracotomy with laparotomy had remarkably high mortality rates of 81.7 and 46.0, respectively. The overall mortality rates for other surgical sites were less than 3.00, and that for cesarean section was 1.8 .

The percentages of the principal causes of death during cardiovascular surgery were $54.0 \%$ due to $\mathrm{PC}$, $36.3 \%$ due to SG, $9.2 \%$ due to IP, and only $0.4 \%$ due to AM; the percentage for thoracotomy with laparotomy were $80.0 \%, 12.0 \%, 8.0 \%$, and $0.0 \%$, respectively. Deaths attributable to AM were limited to five surgical sites (Fig. 5B): cesarean section (1 case), thoracotomy (1), heart and great vessels (1), laparotomy (3), and extremities (1). The principal causes of death included intoxication by local anesthetics, overdose of main anesthetics, hypoventilation, incompatible blood transfusion, and inadvertent high spinal anesthesia.

Table 8. Critical incidents and their outcomes according to surgical site (1999)a

\begin{tabular}{|c|c|c|c|c|c|c|c|c|}
\hline \multirow[b]{2}{*}{ Surgical site } & \multirow[b]{2}{*}{$n$} & \multirow[b]{2}{*}{$\%$} & \multicolumn{2}{|c|}{ Critical incident } & \multicolumn{4}{|c|}{ Outcome $(\%)^{\mathrm{b}}$} \\
\hline & & & $\begin{array}{c}\text { Cardiac } \\
\text { arrest }\end{array}$ & $\begin{array}{l}\text { Other critical } \\
\text { incidents }\end{array}$ & $\begin{array}{l}\text { Uneventful } \\
\text { recovery }\end{array}$ & Death $^{\mathrm{d}}$ & $\begin{array}{c}\text { Vegetative } \\
\text { state }\end{array}$ & Others \\
\hline Craniotomy & 31808 & 4.5 & 21 & 112 & 50.4 & 27.1 & 6.0 & 16.5 \\
\hline Thoracotomy & 23397 & 3.3 & 43 & 101 & 72.2 & 21.5 & 0.0 & 6.3 \\
\hline Heart and great vessels & 27663 & 3.9 & 168 & 516 & 58.6 & 33.0 & 0.6 & 7.7 \\
\hline Thoracotomy with laparotomy & 5430 & 0.8 & 24 & 46 & 54.3 & 35.7 & 0.0 & 10.0 \\
\hline Laparotomy & 222374 & 31.7 & 130 & 608 & 72.5 & 20.5 & 0.4 & 6.6 \\
\hline Cesarean section & 22676 & 3.2 & 6 & 38 & 81.8 & 9.1 & 2.3 & 6.8 \\
\hline Head-neck-ENT & 101835 & 14.5 & 17 & 184 & 90.5 & 4.0 & 0.0 & 5.5 \\
\hline Chest-abdomen-perineum & 77681 & 11.1 & 9 & 96 & 95.2 & 1.9 & 1.0 & 1.9 \\
\hline Spine & 24412 & 3.5 & 7 & 40 & 78.7 & 12.8 & 0.0 & 8.5 \\
\hline Extremities & 115955 & 16.5 & 32 & 165 & 75.1 & 15.2 & 2.0 & 7.6 \\
\hline Others & 48709 & 6.9 & 14 & 50 & 76.6 & 14.1 & 0.0 & 9.4 \\
\hline Total & 701940 & 100.0 & 471 & 1956 & 69.9 & 21.8 & 0.9 & 7.5 \\
\hline
\end{tabular}

${ }^{a}$ Modified with permission from Iwao et al. [10]

${ }^{\mathrm{b}}$ Outcomes are expressed as percentages of patients in each age group

${ }^{\mathrm{c}}$ Including serious hypotension, serious hypoxemia, and others

${ }^{\mathrm{d}}$ Including death in the operating room and death within seven postoperative days

e Including peripheral vascular surgery 
Table 9. Incidences of cardiac arrest and total critical incidents according to surgical site and four major categories of principal cause (1999) a

\begin{tabular}{|c|c|c|c|c|c|c|c|c|c|c|}
\hline \multirow[b]{2}{*}{ Site } & \multicolumn{5}{|c|}{ Cardiac arrest } & \multicolumn{5}{|c|}{ Total critical incidents } \\
\hline & AM & IP & $\mathrm{PC}$ & SG & Total & AM & IP & $\mathrm{PC}$ & SG & Total \\
\hline Craniotomy & 0.94 & 0.94 & 3.14 & 1.57 & 6.60 & 6.92 & 5.03 & 19.18 & 10.69 & 41.81 \\
\hline Thoracotomy & 2.56 & 4.27 & 6.41 & 4.27 & 18.38 & 12.82 & 8.98 & 21.80 & 15.81 & 61.55 \\
\hline Heart and great vessels & 2.89 & 10.12 & 32.53 & 14.46 & 60.37 & 12.29 & 27.47 & 79.89 & 125.80 & 247.26 \\
\hline $\begin{array}{l}\text { Thoracotomy with } \\
\text { laparotomy }\end{array}$ & 0.00 & 11.05 & 25.78 & 7.37 & 44.20 & 9.21 & 23.94 & 60.77 & 34.99 & 128.91 \\
\hline Laparotomy & 0.81 & 1.35 & 2.43 & 1.26 & 5.85 & 8.63 & 4.41 & 11.02 & 8.81 & 33.19 \\
\hline Cesarean section & 1.76 & 0.44 & 0.44 & 0.00 & 2.65 & 7.06 & 3.06 & 6.17 & 1.76 & 19.40 \\
\hline Head-neck-ENT & 0.20 & 0.29 & 0.59 & 0.39 & 1.67 & 9.33 & 2.65 & 4.03 & 3.30 & 19.74 \\
\hline Chest-abdomen-perineum & 0.39 & 0.26 & 0.39 & 0.00 & 1.16 & 6.05 & 1.54 & 3.09 & 2.57 & 13.52 \\
\hline Spine & 0.41 & 1.64 & 0.41 & 0.41 & 2.87 & 11.06 & 2.87 & 2.05 & 3.28 & 19.25 \\
\hline Extremities ${ }^{b}$ & 0.52 & 1.47 & 0.52 & 0.17 & 2.76 & 5.17 & 4.40 & 4.23 & 3.10 & 16.99 \\
\hline Others & 0.62 & 0.21 & 1.03 & 1.03 & 2.87 & 3.90 & 3.08 & 3.28 & 2.67 & 13.14 \\
\hline Total & 0.77 & 1.50 & 2.92 & 1.41 & 6.71 & 7.79 & 4.89 & 10.83 & 10.67 & 34.58 \\
\hline
\end{tabular}

AM, Anesthetic management; IP, intraoperative pathological event; PC, preoperative complication; SG, surgery

${ }^{a}$ The total number of anesthesias was 701940 . Incidences are expressed per 10000 anesthesias

${ }^{\mathrm{b}}$ Including peripheral vascular surgery

A

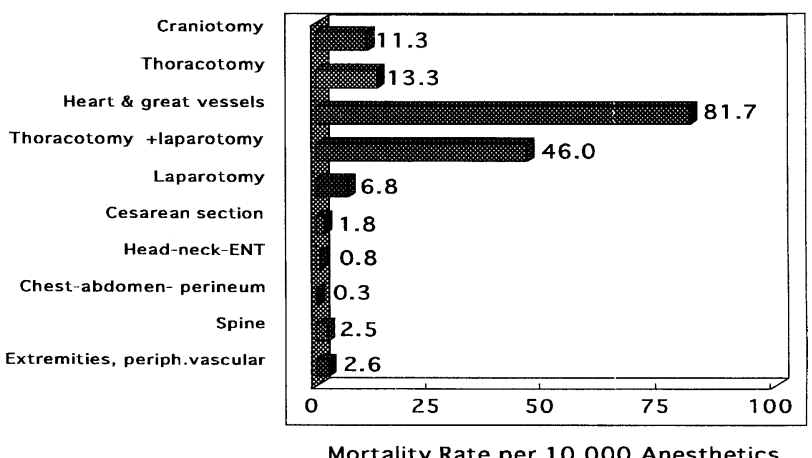

B

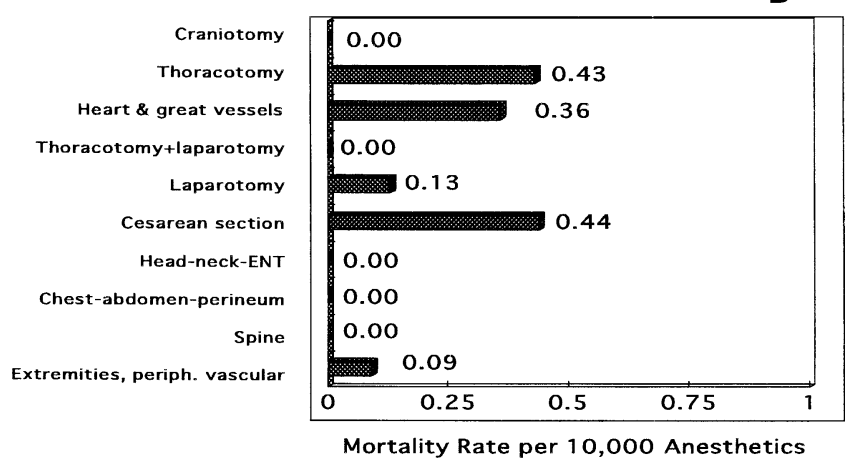

Fig. 5A,B. Mortality rate according to surgical site. A Mortality from any cause. B Mortality totally attributable to anesthetic management $(n=701090)$

Cardiac arrest had the worst outcome after spine surgery, with mortality of $71.4 \%$ within seven postoperative days. It is suspected that the time elapsed before starting cardiopulmonary resuscitation might affect the outcome. The worst prognosis from critical incidents of serious hypotension or hypoxemia occurred after craniotomy, with a mortality rate of $22.3 \%$ and a rate of uneventful recovery of $53.6 \%$. This was probably because serious hypotension or hypoxemia resulting from either central nervous system derangement due to subarachnoid hemorrhage or pre- or intraoperative bleeding could induce fatal damage to the brain.

\section{Analysis according to anesthetic methods}

The number of anesthesias we could analyze according to anesthetic method was 727723 from 520 JSACTHs, $91.7 \%$ of the total anesthesias documented in 1999. General anesthesia accounted for $81.9 \%$, including $31.1 \%$ of cases of general anesthesia with neuraxial/ conduction block, and regional anesthesia accounted for $16.9 \%$. Table 10 summarizes the number of anesthesias, cardiac arrests, other critical incidents, and their outcomes according to anesthetic method. Mortality rates from any cause were 8.17 per 10000 with general anesthesia and 0.81 with regional anesthesia. The mortality rate totally attributable to AM was 0.12 with general anesthesia and 0.08 with regional anesthesia. PC was the principal cause of mortality with general anesthesia $(57.8 \%)$, followed by SG $(28.5 \%)$ and IP $(11.7 \%)$. Only $1.4 \%$ of deaths were totally attributable to AM. The safety of general anesthesia and regional anesthesia has been questioned [23,24]. Recently, from a systematic review of all trials in which patients were randomly assigned to intraoperative neuraxial blockade or not, Rodgers and colleagues [25,26] concluded that the overall mortality was reduced by about one third in patients assigned neuraxial blockade. 
Table 10. Critical incidents and their outcomes according to anesthetic method (1999)

\begin{tabular}{|c|c|c|c|c|c|c|c|c|}
\hline \multirow[b]{2}{*}{ Anesthetic method } & \multirow[b]{2}{*}{$n$} & \multirow[b]{2}{*}{$\%$} & \multicolumn{2}{|c|}{ Critical incidents } & \multicolumn{4}{|c|}{ Outcome $(\%)^{\mathrm{a}}$} \\
\hline & & & $\begin{array}{l}\text { Cardiac } \\
\text { arrest }\end{array}$ & $\begin{array}{c}\text { Critical } \\
\text { incidents }^{\mathrm{b}}\end{array}$ & $\begin{array}{l}\text { Other uneventful } \\
\text { recovery }\end{array}$ & Death $^{\mathrm{c}}$ & $\begin{array}{l}\text { Vegetative } \\
\text { state }\end{array}$ & Others \\
\hline Inhalation & 332776 & 45.7 & 184 & 839 & 68.2 & 22.4 & 1.2 & 8.2 \\
\hline TIVA & 37067 & 5.1 & 127 & 440 & 57.0 & 35.3 & 0.9 & 6.9 \\
\hline $\begin{array}{l}\text { Inhalation with neuraxial/ } \\
\text { conduction block }\end{array}$ & 186195 & 25.6 & 98 & 456 & 83.8 & 8.7 & 0.5 & 7.0 \\
\hline $\begin{array}{l}\text { TIVA with neuraxial/ } \\
\text { conduction block }\end{array}$ & 39699 & 5.5 & 21 & 71 & 84.8 & 10.9 & 0.0 & 4.3 \\
\hline CSEA & 27377 & 3.8 & 2 & 26 & 85.7 & 3.6 & 0.0 & 10.7 \\
\hline Epidural & 17567 & 2.4 & 5 & 26 & 83.9 & 3.2 & 3.2 & 9.7 \\
\hline Spinal & 73836 & 10.2 & 12 & 89 & 87.1 & 6.9 & 2.0 & 4.0 \\
\hline Conduction block & 3961 & 0.5 & 1 & 5 & 66.7 & 16.7 & 0.0 & 16.7 \\
\hline Others & 9245 & 1.2 & 43 & 31 & 21.6 & 73.0 & 0.0 & 5.4 \\
\hline Total & 727723 & 100.0 & 493 & 1983 & 69.5 & 22.3 & 0.9 & 7.3 \\
\hline
\end{tabular}

TIVA, Total intravenous anesthesia; CSEA, combined spinal epidural anesthesia

${ }^{a}$ Outcomes are expressed as percentages of patients in each anesthetic methods group

${ }^{\mathrm{b}}$ Including serious hypotension, serious hypoxemia, and others

${ }^{\mathrm{c}}$ Including death in the operating room and death within seven postoperative days

Table 11. Incidences of cardiac arrest and total critical incidents according to anesthetic method and four major categories of principal cause $(1999)^{\mathrm{a}}$

\begin{tabular}{|c|c|c|c|c|c|c|c|c|c|c|}
\hline \multirow[b]{2}{*}{ Anesthotic method } & \multicolumn{5}{|c|}{ Cardiac arrest } & \multicolumn{5}{|c|}{ Total critical incidents } \\
\hline & $\mathrm{AM}$ & IP & $\mathrm{PC}$ & $\mathrm{SG}$ & Total & $\mathrm{AM}$ & IP & $\mathrm{PC}$ & SG & Total \\
\hline Inhalation & 0.51 & 1.17 & 2.37 & 1.29 & 5.53 & 7.06 & 4.54 & 11.90 & 6.82 & 30.74 \\
\hline TIVA & 0.35 & 3.51 & 22.66 & 6.47 & 34.26 & 7.01 & 10.52 & 55.84 & 79.05 & 152.97 \\
\hline $\begin{array}{l}\text { Inhalation with neuraxial/ } \\
\text { conduction block }\end{array}$ & 0.97 & 2.04 & 0.81 & 1.40 & 5.26 & 9.67 & 5.53 & 4.94 & 9.24 & 29.75 \\
\hline $\begin{array}{l}\text { TIVA with neuraxial/ } \\
\text { conduction block }\end{array}$ & 1.51 & 2.27 & 0.00 & 1.57 & 5.29 & 8.56 & 3.53 & 4.03 & 6.82 & 3.17 \\
\hline CSEA & 0.73 & 0.00 & 0.00 & 0.00 & 0.73 & 4.38 & 1.10 & 2.92 & 0.37 & 10.23 \\
\hline Epidural & 1.71 & 0.57 & 0.00 & 0.57 & 2.85 & 9.68 & 2.28 & 2.85 & 2.85 & 17.65 \\
\hline Spinal & 0.54 & 0.81 & 0.14 & 0.14 & 1.63 & 4.47 & 3.66 & 1.63 & 3.79 & 13.68 \\
\hline Conduction block & 2.52 & 0.00 & 0.00 & 0.00 & 2.52 & 10.10 & 0.00 & 5.05 & 0.00 & 15.15 \\
\hline Others & 1.08 & 3.24 & 36.87 & 5.41 & 46.51 & 4.33 & 7.57 & 57.33 & 9.73 & 80.04 \\
\hline Total & 0.78 & 1.50 & 2.93 & 1.46 & 6.77 & 7.49 & 4.78 & 10.87 & 10.47 & 34.02 \\
\hline
\end{tabular}

AM, Anesthetic management; IP, intraoperative pathological event; PC, preoperative complication; SG, surgery; TIVA, total intravenous anesthesia; CSEA, combined spinal epidural anesthesia

a Total number of anesthesias was 727723 . Incidences are expressed per 10000 anesthesias

There were notable differences in the incidence of critical events and mortality due to all events between patients receiving general anesthesia by inhalation and those receiving TIVA. The incidence of cardiac arrest per 10000 due to any cause was 5.53 for inhalation anesthesia $(n=332776)$ and 34.26 for TIVA $(n=$ 37076) (Table 11). The mortality rates from cardiac arrest within seven postoperative days due to any cause were 2.82 for inhalation anesthesia and 24.55 for TIVA. The incidence of serious hypotension was 13.61 and 100.36 for inhalation anesthesia and TIVA, respectively. The mortality rates from other critical incidents due to any cause were 4.06 for inhalation anesthesia and 29.41 for TIVA. The overall mortality rates in all patients were 6.88 and 53.96, respectively. Among patients receiving neuraxial/conduction block, there were no differences between those receiving inhalation anesthesia and those receiving TIVA in the incidence of and mortality from cardiac arrest, other critical incidents, and total incidents due to any cause. These remarkable differences between patients receiving inhalation anesthesia and those receiving TIVA were not found in the incidences of and mortality from critical events totally attributable to AM, but they were found in those due to 


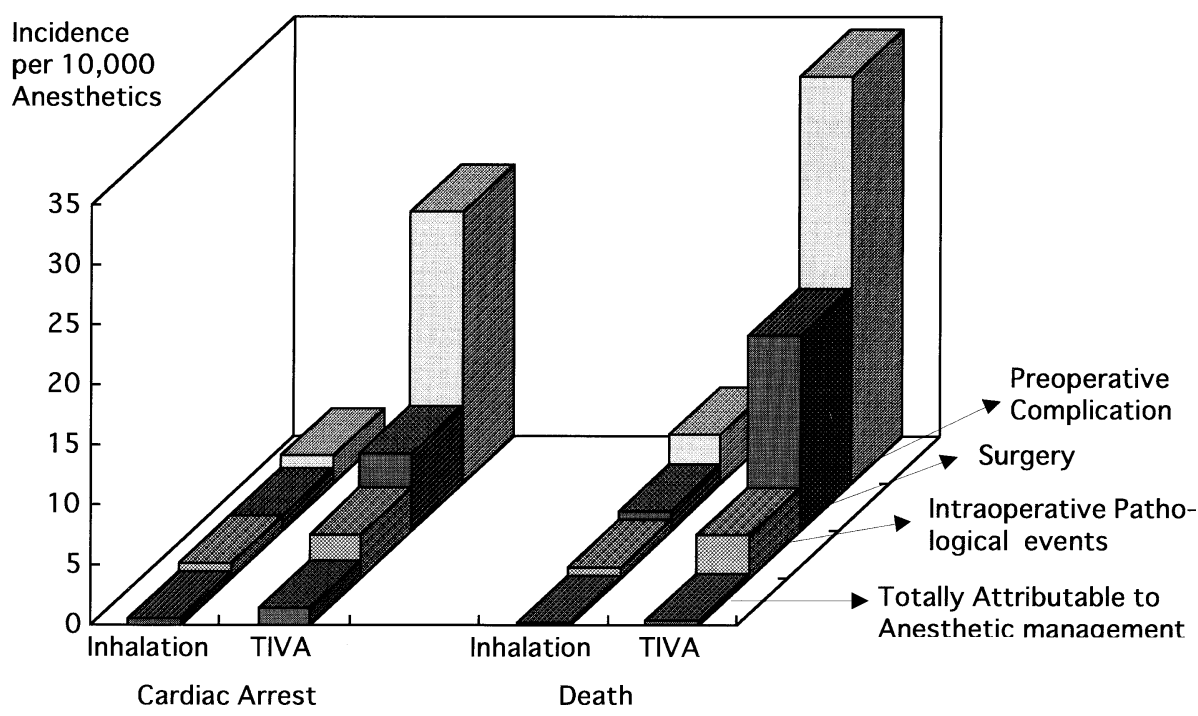

Fig. 6. Comparison of incidence of cardiac arrest and death per 10000 anesthesias between patients receiving inhalation anesthesia $(n=$ $332776)$ and those receiving total intravenous anesthesia $(T I V A)(n=$ 37076) the other three major categories of principal causes, IP, PC, and SG. PC contributed the most to the high incidence and mortality, followed by SG, then IP (Fig. $6)$.

Because the incidence totally attributable to AM did not show a significant difference, TIVA itself is not believed to be dangerous. However, Cohen et al. [21] demonstrated that receiving a narcotic technique and receiving only one or two anesthetic drugs were determinants of the independent predictors of mortality in elective, non-major cases with ASA-PS of 1,2 , or 3 . The cause of the difference in mortality and morbidity between patients receiving TIVA and those receiving inhalation anesthesia in our study was most probably due to the uneven distribution of patients as to ASA-PS classification, age group, surgical procedure, and the combination of those factors. To confirm this hypothesis, multiple analysis of variance should be performed. However, this is impossible with our present database, because the distribution of patients without critical incidents was not documented. To achieve this, the entire register must be provided from all hospitals, which is impossible and impractical because of the difficulty of protecting the confidentiality of the data. Further studies will be needed to elucidate the cause of the higher incidence of critical events in patients receiving TIVA.

The Annual Study of Anesthesia-related Mortality and Morbidity (ASARMM) by JSACORS will be continued for five consecutive years using the same confidential questionnaires. We believe that this series of studies will provide valuable information as to perioperative patient safety, but we also believe that a new survey will be needed to analyze the precise mechanism of mortality and morbidity.

\section{Summary}

The 793847 anesthesia cases collected from 460 anesthesia training hospitals in Japan in 1999 were analyzed. The incidences of cardiac arrest, other critical events (for example, severe hypotension or hypoxemia), and death from any cause were $6.53,26.53$, and 7.19 per 10000 anesthesias, respectively. The incidences of these events attributable to the anesthetic procedure were $0.78,6.71$, and 0.13 , respectively. Among the four major categories of principal causes of incidents, the outcome was worst for those due to preoperative complication, followed by those due to intraoperative events, then those due to surgery. The best prognosis was found for incidents due to anesthetic procedure. The rates of cardiac arrest and death totally attributable to anesthesia in Japan are comparable to those of other developed countries. To further improve anesthesia-related mortality and morbidity, we should pay more attention to improving preanesthetic assessment and preparation for cardiovascular conditions, in addition to being vigilant to avoid human errors.

\section{References}

1. Japanese Society of Anesthesiologists Committee on Operating Room Safety (1996) Annual study of anesthesia-related mortality and morbidity 1994 (in Japanese). Masui (Jpn J Anesthesiol) 45:1538-1548

2. Japanese Society of Anesthesiologists Committee on Operating Room Safety (1997) Annual study of anesthesia-related mortality and morbidity 1995 (in Japanese). Masui (Jpn J Anesthesiol) 46:423-434

3. Japanese Society of Anesthesiologists Committee on Operating Room Safety (1998) Annual study of anesthesia-related mortality and morbidity 1996 (in Japanese). Masui (Jpn J Anesthesiol) 47:1379-1390 
4. Japanese Society of Anesthesiologists Committee on Operating Room Safety (1999) Annual study of anesthesia-related mortality and morbidity 1997 (in Japanese). Masui (Jpn J Anesthesiol) 48:309-322

5. Japanese Society of Anesthesiologists Committee on Operating Room Safety (2000) Annual study of anesthesia-related mortality and morbidity 1998 (in Japanese). Masui (Jpn J Anesthesiol) 49:432-444

6. Kawashima Y, Takahashi S, Suzuki M (2001) Anesthesia-related mortality and morbidity: analysis in 2363038 anesthetics over a 5year period in Japan (in Japanese). Nihon Iji Shinpou 4026:2129

7. Irita K, Kawashima Y, Kobayashi T, Goto Y, Morita K, Iwao Y, Seo N, Tsuzaki K, Dohi S (2001) Perioperative mortality and morbidity for the year of 1999 in 466 Japanese certified anesthesia-training hospitals: with special reference to ASAphysical status. Report of Committee on Operating Room Safety of Japan Society of Anesthesiologists (in Japanese with English abstract). Masui (Jpn J Anesthesiol) 50:678-691

8. Morita K, Kawashima Y, Irita K, Kobayashi T, Goto Y, Iwao Y, Seo N, Tsuzaki K, Dohi S (2001) Perioperative mortality and morbidity in 1999 with a special reference to age in 466 certified training hospitals of Japanese Society of Anesthesiologists. Report of Committee on Operating Room Safety of Japanese Society of Anesthesiologists (in Japanese with English abstract). Masui (Jpn J Anesthesiol) 50:909-921

9. Seo N, Kawashima Y, Irita K, Kobayashi T, Goto Y, Morita K, Iwao Y, Tsuzaki K, Dohi S (2001) Annual report of perioperative mortality and morbidity for the year 1999 with a special reference to anesthetic methods at certified training hospitals of Japanese Society of Anesthesiologists (in Japanese with English abstract). Masui (Jpn J Anesthesiol) 50:1028-1037

10. Iwao Y, Kawashima Y, Irita K, Kobayashi T, Goto Y, Morita K, Seo N, Tsuzaki K, Dohi S (2001) Perioperative mortality and morbidity for the year 1999 in 466 Japanese certified anesthesia-training hospitals: with special reference to operative regions. Report of Committee on Operating Room Safety of Japanese Society of Anesthesiologists (in Japanese with English abstract). Masui (Jpn J Anesthesiol) 50:11441153

11. Kawashima Y, Seo N, Morita K, Iwao Y, Irita K, Tsuzaki K, Dohi S, Goto Y, Kobayashi T, Dohi S (2001) Annual study of perioperative mortality and morbidity for the year of 1999 in Japan: the outlines. Report of the Japan Society of Anesthesiologists Committee on Operating Room Safety (in Japanese with English abstract). Masui (Jpn J Anesthesiol) 50:12601274

12. Kawashima Y, Irita K, Morita K, Seo N, Iwao Y (2002) A comment on five reports concerning perioperative mortality and morbidity of the year 1999 in Japanese Society of Anesthesiologists certified training hospitals (in Japanese with English abstract). Masui (Jpn J Anesthesiol) 51:557-559

13. Tirret L, Desmonts JM, Hatton F, Vourc'h G (1986) Complications associated with anesthesia-a prospective survey in France. Can Anaesth Soc J 33:336-344

14. Lunn JH, Devlin HB (1987) Lessons from the confidential enquiry into perioperative deaths in three NHS regions. Lancet 2:1384-1386

15. Holland R (1987) Anesthetic mortality in New South Wales. Br J Anaesth 59: 834-841

16. Warden JC, Horan BF (1996) Deaths attributed to anesthesia in New South Wales, 1984-1990. Anaesth Intens Care 24:66-73

17. Eagle CCP, Davis NJ (1997) Report of the anaesthetic mortality committee of Western Australia 1990-1995. Anaesth Intens Care 25:51-59

18. Tikkanen J, Hovi-viander M (1995) Death associated with anaesthesia and surgery in Finland in 1986 compared to 1975. Acta Anaesthesiol Scand 39:262-267

19. Olsson GL, Hallen B (1988) Cardiac arrest during anaesthesia. A computer aided study in 250543 anaesthetics. Acta Anaesthesiol Scand 32:653-664

20. Biboulet P, Aubas P, Dubourdieu J, Rubenovitch J, Capdevila X, d'Athis F (2001) Fatal and non fatal cardiac arrests related to anesthesia. Can J Anesth 48:326-332

21. Cohen MM, Duncan PG, Tate RB (1988) Does anesthesia contribute to operative mortality? JAMA 260: 2859-2863

22. Keenan RL, Boyan CP (1985) Cardiac arrest due to anesthesia. A study of incidence and causes. JAMA 253:2373-2377

23. Atanassoff PG (1996) Effects of regional anesthesia on perioperative outcome. J Clin Anesth 8:446-455

24. Roy RC (2000) Choosing general versus regional anesthesia for the elderly. Anesthesiol Clin North Am 18:91-104

25. Urwin SC, Parker MJ, Griffiths R (2000) General versus regional anaesthesia for hip fracture surgery: a meta-analysis of randomized trials. Br J Anaesth 84:450-455

26. Rodgers A, Walker N, Schug S, McKee H, Kehler H, van Zundert A, Sage D, Futter M, Saville G, Clark T, MacMahon S (2000) Reduction of postoperative mortality and morbidity with epidural or spinal anesthesia: results from overview of randomized trials. BMJ 321:1493-1497 